\title{
A PRELIMINARY FORENSIC-PSYCHIATRIC STUDY OF SEXUAL OFENDERS IN OPORTO, PORTUGAL
}

Lascasas D.

ULSกA

Unidade Local de Saúde do Norte Alentejano EPE, Departamento de Psiquiatria e Saúde Mental, Portalegre, Portugal

\section{Background:}

A substantial proportion of sexual offenders (SO) exhibit mental disorders, such as personality disorders, substance abuse, mood disorders and compulsive sexual behavior (1-3). Thus, the role of mental disorders in forensic assessment of the level of penal responsibility of SO is of crucial importance.

\section{Objetive:}

To characterize from a sociodemographic, clinical and criminal perspective a forensic sample of sexual offenders.

\section{Materials and Methods:}

A preliminary descriptive cross-sectional study of a sample of 121 individuals charged with having committed sexual crimes and referred to two psychiatric hospitals from Oporto district, Portugal, for forensic psychiatric assessment, drawn from a total of 3146 forensic psychiatric assessments carried out from 1986 to 2016.
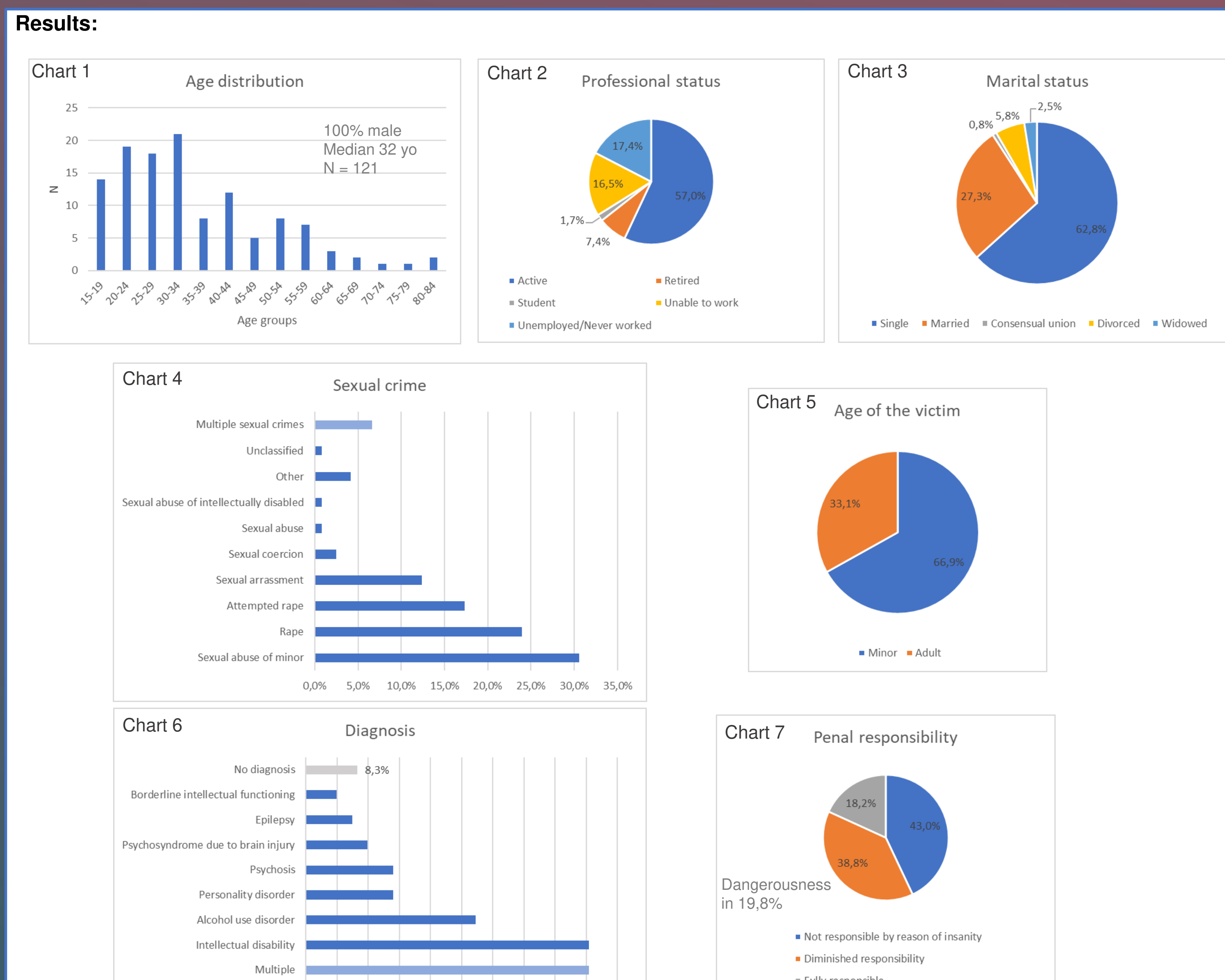

$0,0 \% 5,0 \% 10,0 \% 15,0 \% 20,0 \% 25,0 \% 30,0 \% 35,0 \% 40,0 \% 45,0 \% 50,0 \%$

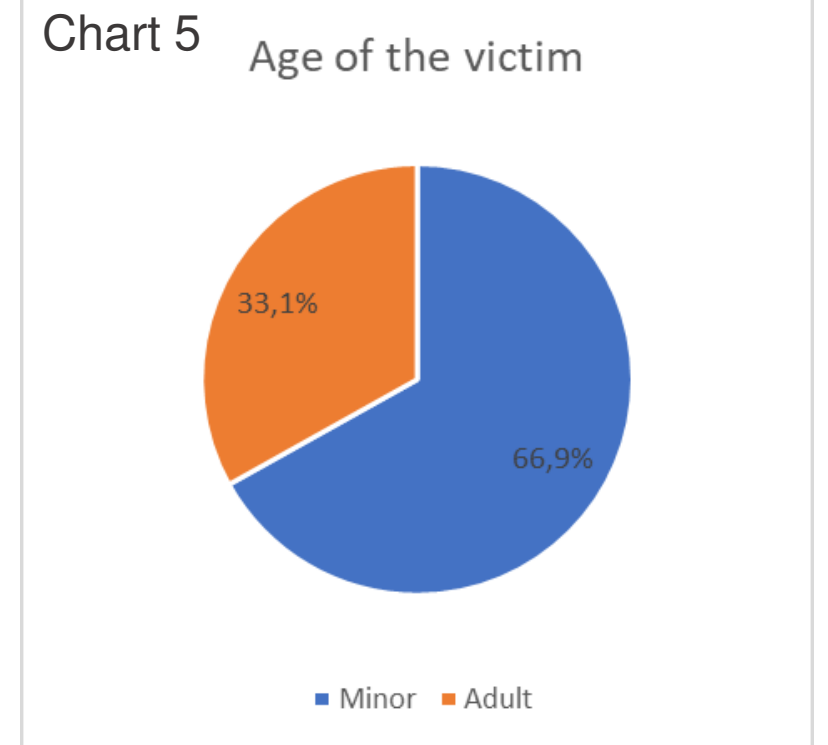

Chart 7 Penal responsibility

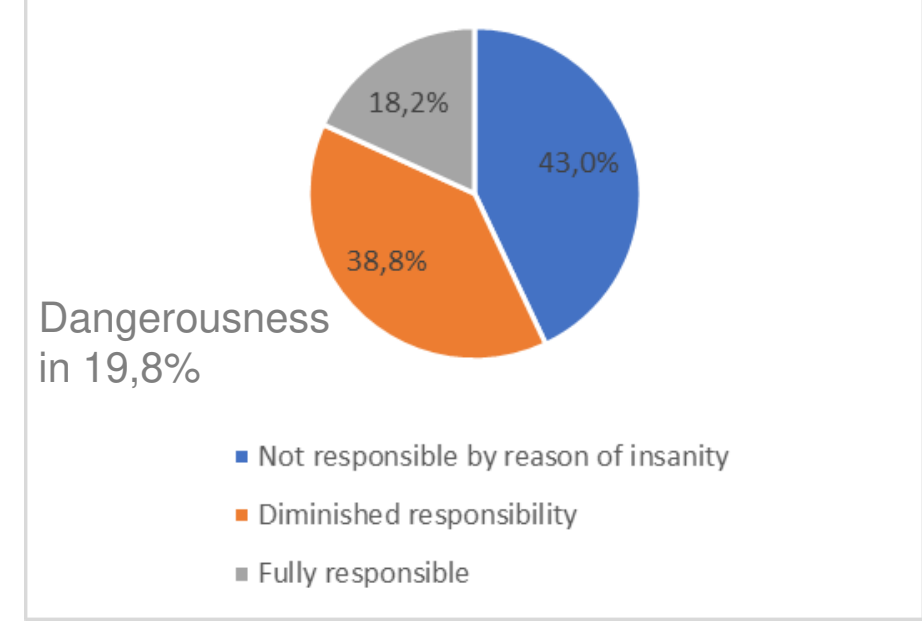

Conclusion: The profile of the portuguese sexual ofender submitted to forensic psychiatric assessment was male, young, professionally active, single and mentally disturbed, with minors being the most common victims. Mental disorders do not, in most cases, lead to penal non-responsability, but there are important forensic repercussions on the attribution of imputability mitigation.

\section{Sources:}

1) Valença $A M$, et al. A forensic-psychiatric studdy of sexual offenders in Rio de Janeiro, Brazil. J Forensic Leg Med. 2015;31:23-8.

2) McElroy SL, et al. Psychiatric features of 36 men convicted os sexual offenses. J Clin Psychiatry 1999;60:414e20.

3) Holoyda BJ; McDermott BE; Newmann WJ. Insane Sex Offenders: Psychiatric and Legal Characteristics of Sexual Offenders Found Not Guilty by Reason of Insanity. J Forensid Sci. 2018 jul; 63(4):1207-1214. 